ISSN: 0213-1854

\title{
The Rape of the Lock de Alexander Pope y la primera (re)traducción al español de 1839, basada en una traducción francesa
}

\section{(The Rape of the Lock by Alexander Pope and the first version into the Spanish, 1839, based on a French translation)}

\author{
ÁNGELES GARCía CALDERÓN/ EMILIA MARía SÁNCHEZ JiMÉNEZ \\ id1gacaa@uco.es/192sajie@uco.es \\ Universidad de Córdoba
}

Fecha de recepción: 27 de octubre de 2018

Fecha de aceptación: 30 de noviembre de 2018

Resumen: The Rape of the Lock, poema narrativo de Alexander Pope, satiriza las tradiciones de la épica clásica: el rapto de Helena de Troya es aquí el robo de un mechón de pelo; los dioses se transforman en diminutas silfides; el viaje de Eneas hasta el Tíber se convierte en el viaje de Belinda hasta el Támesis y la descripción del escudo de Aquiles pasa a ser la descripción de las enaguas de Belinda. De la obra hay cinco versiones al español: dos del siglo XIX, una de traductor desconocido con el título de El bucle arrebatado (1839), y otra del humanista canario Graciliano Afonso Naranjo, El rizo robado (1851). Las dos últimas son del siglo XXI: pertenecen una al poeta peruano César Gilberto Saldaña Fernández, El robo del bucle, publicada en Lima por la Pontificia Universidad Católica del Perú, 2002; la última, de 2017, incluida en el volumen Ensayo sobre el hombre y otros escritos de Alexander Pope (Madrid: Editorial Cátedra, "Colección Letras Universales") cuya autoría corresponde a A. Lastra y a Á. García. El trabajo analiza la similitud de la retraducción española de 1839, que sigue de modo muy fiel a una francesa de 1763, lo que ya afirma el anónimo autor en su prólogo. Desde este punto de vista, se analiza la estructura de la traducción francesa y de la retraducción al español, así como los errores morfosintácticos de una y otra.

Palabras clave: Poesía inglesa. Sátira. Traducción. Retraducción.

Abstract: The Rape of the Lock is a narrative poem written by the famous Alexander Pope, in which many Classical epic traditions are satirized. Among those satires which the poem compiles about the Classical world and the Classical 


\section{ÁNGeles GarCía CALDERÓN / EMILIA MARía SÁNCHEZ JiMÉNEZ}

tradition arise such as the abduction of Helen of Troy, which is now reproduced in verses by means of the robbery of the lock; Gods are turned into miniscule sylphs; Aenea's voyage across the Tiber is compared to Belinda's journey throughout River Thames; or the description of Achilles's Shield, which is equivalent now to the description of Belinda's petticoats. There are five available versions of the original poem into the Spanish language: two of them date from the nineteenth-century; the first one - from anonymous translator, is entitled El bucle arrebatado (1839), meanwhile the second one was carried out by the Canaryan humanist Graciliano Afonso, El rizo robado (1851). The last two versions of the poem go back to the twenty-first century; the first one belongs to the Peruvian poet César Gilberto Saldaña Fernández, El robo del bucle, which was published by the Catholic University of Peru, 2002, Lima. Finally, the last version of the original poem dates from 2017, and it is included in the volume Ensayo sobre el hombre y otros escritos de Alexander Pope (Madrid: Editorial Cátedra, "Colección LetrasUniversales") by A. Lastra y Á. García. The essay is focused on the examination of the similitude which the Spanish retranslation (1839) shares with the former and original French version (1763), which is faithfully imitated by the anonymous Spanish author as he declares in the prologue to his poem.

From this view, both - the structure of the French translation and its retranslation into Spanish, as well as those morphosyntactic errors included along - the poem are analysed.

Key words: English poetry. Satire. Translation. Retranslation.

\section{Introducción}

En The Rape of the Lock, poema narrativo de Alexander Pope, el escritor satiriza una pequeña disputa comparándola con el épico mundo de los dioses. El tema está basado en un incidente contado por el amigo de Pope, John Caryll: Arabella Fermor y su pretendiente, Lord Petre, los protagonistas, provenían de familias aristocráticas y católicas en un periodo de Inglaterra en el que la religión católica estaba prohibida. Petre, loco de amor por Arabella, le corta un mechón sin permiso de ella, lo que da lugar a un conflicto entre las dos familias. En la obra Belinda representa a Arabella, introduciendo Pope como personajes secundarios a un grupo de sílfides, o espíritus guardianes de las vírgenes, una versión en clave de parodia de los cuentos épicos tradicionales sobre dioses. El poema de Pope satiriza las tradiciones de la épica clásica: el rapto de Helena de Troya es aquí el robo de un mechón de pelo; los dioses se transforman en diminutas sílfides; el viaje de Eneas hasta el Tíber se convierte en el viaje de Belinda hasta el Támesis y 
The Rape of the Lock de Alexander Pope y la primera (re)traducción al español...

la descripción del escudo de Aquiles pasa a ser la descripción de las enaguas de Belinda.

De The Rape of the Lock hay cinco versiones al español: dos del siglo XIX, una de traductor desconocido con el título de El bucle arrebatado (Omaña 1839), y otra en verso del humanista canario Graciliano Afonso Naranjo, El rizo robado (Afonso Naranjo 1851). Una del siglo XX perteneciente a Enrique García Díaz, licenciado en Filología Inglesa por la Universidad de Salamanca, donde llevó a cabo su doctorado en 2007, y disponible en internet (García Díaz 2018). Las dos últimas, del siglo XXI, pertenecen una al poeta peruano César Gilberto Saldaña Fernández (2002), El robo del bucle, publicada en Lima por la Pontificia Universidad Católica del Perú; la última aparece incluida en el volumen Ensayo sobre el hombre y otros escritos de Alexander Pope (Lastra y García Calderón 2017).

\section{La traducción francesa}

En el final del prólogo del anónimo retraductor español podemos leer lo siguiente:

No tengo noticia de que se haya traducido al español este poema, entre tantas obrillas como se han dado a conocer entre nosotros - La celebridad del Rizo arrebatado de Pope, avivaba más y más nuestros deseos por leerle; no poseíamos el inglés, pero se nos había la mejor traducción francesa (Obras diversas de Pope traducidas del inglés; tomo II edición de Ámsterdam. Año de 1763) hecha en prosa con la mayor fidelidad y exactitud. Y Habiéndonos parecido la inspiración de tanto mérito, no hemos dudado darla a conocer entre nosotros, en tanto que otro se dedica a trasladarla del original, con más acierto y maestría (traducción anónima, 1839).

Conocido el dato de la ciudad y la fecha de referencia, una búsqueda adecuada nos conduce al Dictionnaire des ouvrages anonymes et psendonymes. Composés, traduits on publiés en français, avec les noms des Auteurs, Traducteurs et Éditeurs; Accompagné de notes historiques et critiques (Barbier 1806: 157) donde podemos leer las dos referencias siguientes:

5158. Euvres diverses de M. Pope (à savoir, ses Épîtres morales traduites en prose par D'Aine, avec la Traduction en vers de la Boucle de cheveux enlevée, par Marmontel). Paris, Nyon, 1753, petit in-12. 


\section{Ángeles García CALDERÓN/ Emilia María SÁNCHEZ JiMÉNEZ}

5159. CEuvres diverses de M. Pope, traduites de l'anglais (par différents Auteurs, recueillies par Élie de Joncourt). Amsterdam, Arkstéeet-Merkus,1754,7, vol.in-12. Nouvelle édition augmentée. Amsterdam, 1767,8, vol.in-12.

Otra referencia posterior alude a la misma obra:

Cuvres diverses d'Alexandre Pope, traduites de l'anglais (De Joncourt Elie 1754: 191) ${ }^{1}$.

Creemos que no se trata del primer ejemplo mencionado en el libro de Barbier, ya que la traducción de Marmontel es en verso ${ }^{2}$. Pero, además de las traducciones citadas, de 1754 la primera y de 1767 la segunda, el retraductor ${ }^{3}$ español debía conocer otra versión de 1763, cuyo título completo es: CEuvres diverses de Pope, traduites de l'anglais. Nouvelle édition, Augmentée de plusieurs pièces et de la vie de l'auteur: Avec de très belles Figures en taille douce. Tome Second, à Amsterdam et à Leipzig ${ }^{4}$ (Arkstée; Merkus 1763).

Este segundo tomo de las Euvres diverses de Pope, contiene las siguientes traducciones: Essai sur l'homme; Les Principes du Goût, ou Essai sur la Critique, traduit par M. Duresnel; La Boucle de Cheveux enlévée, Poème Héroï-Comique de M. Pope, traduit de l'anglais par M.***; Le même traduit en Vers Français par M.***.

Así pues, en las dos versiones de la obra de Pope recopiladas por Élie de Joncourt el firmante viene marcado por tres asteriscos, práctica habitual para enmascarar el anonimato de un autor; no obstante, una breve búsqueda nos muestra que la versión en verso pertenece a Marmontel, modalidad en la que el escritor y dramaturgo francés era un maestro consumado ${ }^{5}$.

${ }^{1}$ Catalogue de la Bibliothèque de la Ville de Grenoble. Grenoble: Imprimerie de C.-P. Baratier, Tome II, 1835 , p. 191

2 Jean-François Marmontel (1723-1799), poeta, narrador, dramaturgo, filósofo y traductor de un gran conocimiento sobre el siglo XVIII. Contribuyó enormemente en la redacción de L'Encyclopédie con casi 200 artículos de literatura, lingüística y filosofía. Marmontel fue quien redactó en el famoso diccionario el artículo "Traduction" (volumen IV del Supplément de l'Encyclopédie, 1777, y que ampliaba bastante el que había redactado el gramático Nicolas Beauzée para la primera edición, vol. XVI, 1765).

${ }^{3}$ Sobre la traducción de Pope al español a través de una traducción previamente realizada en francés puede consultarse el trabajo de Torralbo Caballero (2018: 509-531) que aborda el caso de The Dunciad a manos de Alberto Lista.

${ }^{4}$ Ciudad que no mencionan ni los traductores franceses ni el retraductor español.

${ }_{5}$ Así aparece como autor en el volumen titulado: Petits poètes français, depuis Malherbes (sic) jusqu'à nos jours, avec des notices biographiques et littéraires sur chacun d'eux par M. Prosper Poitevin. Tome Premier. 
The Rape of the Lock de Alexander Pope y la primera (re)traducción al español...

Aunque el análisis general versa sobre toda la traducción francesa y su retraducción al español, la transcripción del prólogo y el primer canto de cada una de ellas, proporcionará al lector una idea más aproximada de las similitudes y diferencias entre ellas. Para ello, veamos la transcripción de la traducción francesa, y posteriormente su retraducción al español.

\section{PREFACE DU TRADUCTEUR}

Voici la traduction d'un petit Poème Anglais de l'illustre Mr. Pope, le premier Poète moderne d'Angleterre. Entre autres Ouvrages qu'il a donnés au public, il est Auteur de la traduction en vers Anglais de l'Iliade d'Homère, qui a été si justement louée par Monsieur de Voltaire dans son Essai sur la Poésie Épique, traduit nouvellement de l'Anglais en François, \& imprimé à Paris. On vient aussi de traduire \& de publier les Discours sensés \& ingénieux dont Monsieur Pope a accompagné sa traduction de l'Iliade, \& on est obligé d'avouer qu'on n'a jamais rien écrit de plus judicieux en faveur d'Homère.

La traduction de ce Poème Héroï-comique, intitulé en Anglais The Rape of the Lock, pourra contribuer à faire voir l'erreur du préjugé où nous sommes, que la Nation Anglaise n'a en partage que le sérieux \& le profond, \& ne peut atteindre comme nous à la fine plaisanterie, à la satyre délicate, \& à l'élégant badinage. Il est vrai que les Voyages de Gulliver ont déjà commencé à nous détromper; mais comme ils n'ont pas été publiés en Français tels qu'ils ont paru en Anglais, \& que le Traducteur de son aveu a beaucoup retranché \& beaucoup ajouté, le succès que ce Livre a eu en France, en faisant honneur à Monsieur Swift, qui en est l'Auteur, nous a toujours laissé croire que son ouvrage avait besoin qu'on y mît la main, surtout depuis qu'on a vu a Paris ces mêmes Voyages de l'édition d'Hollande, traduits fidèlement\& mot à mot.

Il n'en sera pas de même de la traduction qu'on donne ici du Rape of the Lock, qui est très littérale. On n'a rien ajouté, ni rien retranché;\& si elle renferme quelques différences, elles sont légères\& dans les règles. Car il est hors de doute, que lorsqu'on traduit, il est quelquefois nécessaire de préférer les expressions équivalentes à celles qui répondent

Paris: Auguste Desrez, 1838. En la página 407 se transcribe el poema, figurando como autor Marmontel. 


\section{Ángeles García CALDERón/ Emilia María SÁNCheZ JimÉNEZ}

directement \& immédiatement aux termes de l'original; sans quoi une traduction, pour être trop scrupuleusement fidèle, deviendrait réellement infidèle, \& déshonorerait injustement l'Auteur qu'on traduit.

Je ne crois pas qu'on trouve rien dans notre langue de plus ingénieux, dans le genre badin, que la Boucle enlevée de Mr. Pope, qui, lorsqu'il fit ce petit Poème, n'avait, dit-on, que vingt ans: seul âge où il convient de s'amuser à faire des vers de cette espèce, \& peut-être de quelque espèce que ce soit. Ce qui fit éclore cet ouvrage, fut une aventure arrivée en 1712 à Madame Femor à laquelle il le dédia. La médiocrité d'un sujet aussi stérile en apparence, ne servit qu'à faire estimer davantage le génie \& le bel esprit de l'Auteur. Le Poème de la Boucle enlevée est parmi les Anglais ce que le Lutrin est parmi nous, si ce n'est qu'il est, ce semble, plus enjoué \& plus galant.

Il eût peut-être été à propos de le traduire en vers; mais outre que le travail eût été plus pénible, on n'avait pas lieu d'espérer d'y réussir. D'ailleurs, une prose poétique frappe également l'imagination, \& a une certaine liberté que nos vers n'ont point.

Quoique cette traduction soit fort au défi sous de l'original, on présume qu'elle plaira, parce que les beautés de l'Auteur couvriront les défauts du traducteur.

On trouvera, dans ce petit Poème, de l'invention, du dessein, de l'ordre, du merveilleux, de la fiction, des images \& des pensées, en un mot, ce qui constitue la vraie poésie. On y remarquera un comique riant, fort éloigné du fade burlesque, des allusions satyriques sans être offensantes, des plaisanteries hardies fans être trop libres, \& des railleries délicates sur le Beau sexe, peut-être plus capables de lui plaire, que toutes les fleurettes de nos Madrigaux \& de nos Bucoliques modernes.

Nous n'avons point encore vu de Poème, dont le merveilleux, \& ce que les Anglais appellent the machinery, fût tiré du système imaginaire des Cabalistes: l'usage qu'en a fait Monsieur Pope, montre que ces idées font très favorables à la Poésie; mais il faut avouer aussi, que ce n'est que dans un Poème de ce genre qu'elles peuvent avoir lieu. Au reste on voit dans l'Épître Dédicatoire de Mr. Pope, que de son 
The Rape of the Lock de Alexander Pope y la primera (re)traducción al español...

aveu il a beaucoup profité du Livre de l'Abbé de Villars, intitulé Le Comte de Gabalis ${ }^{6}$.

On espère que ce petit ouvrage ne plaira pas seulement aux Dames, mais qu'il fera même estimé de ceux qui ne regardent un Vaudeville qu'avec des yeux savants: ils y verront toutes les proportions observées, comme dans le Poème le plus sérieux, \& tous les grands principes de l'Epopée suivis fidèlement, Celui qui publie aujourd'hui ce Poème en Français, attend du public la reconnaissance due à un Voyageur qui apporte dans sa patrie une fleur des pays étrangers.

LA BOUCLE DE CHEVEUX ENLEVÉE, POÈME HÉROÏ-COMIQUEDE MONSIEUR POPE, Traduit de L'Anglais par M. ***

Nolueram Belinda tuosviolare capillos;

Sed juvat ocprecibus me tribuisse tuis.

MARTIAL

\section{CHANT PREMIER}

Je chante une cruelle offense causée par l'Amour, \&une querelle sérieuse née d'une hardiesse badine. Muse, je consacre ces vers à Tirsis, \& je me flatte que Belinde daignera les lire. Quoique je traite de petites choses, je mériterai de grands éloges, si l'une m'inspire, \& si l'autre m'applaudit.

Ô Déesse, dis-moi quel étrange motif porta un jeune Seigneur à attaquer une Belle. Apprends-moi quelle cause encore plus extraordinaire, força la Belle à résister au jeune Seigneur. Peut-il y avoir tant de dureté dans un cœur tendre, $\&$ tant de courage dans un Petit-maître?

Le Soleil perçoit au travers de rideaux blancs\&par de timides rayons essayait d'ouvrir ces yeux qui le devaient éclipser. Déjà, les chiens favoris secouaient leurs oreilles; les amants, qui se plaignent de ne dormir jamais, commençaient à s'éveiller: il était midi. Trois fois les pantoufles avoient frappé le plancher; trois fois les sonnettes avaient appelé, \& les montres pressées du doigt

${ }^{6}$ Le Comte de Gabalis, cuyo título completo es Le Comte de Gabalis on Entretiens sur les sciences secrètes, es una sátira social publicada anónimamente en 1670. Posteriormente se supo el nombre de su autor: Henri de Montfaucon, apodado el Abbé de Villars (c.1638-1673).

El libro se componía de cinco discursos de un maestro espiritual a su discípulo, siendo considerado como un texto perteneciente a la orden rosa cruz, de naturaleza cabalística. Se trata del primer libro en la literatura francesa en el que se mencionan a los silfos, criaturas ficticias que pululan en el aire. 


\section{Ángeles García CALDERÓN/ Emilia María SÁNCheZ JiMÉNEZ}

avoient fait entendre leur son argentin. Cependant Belinde, languissamment étendue sur ce duvet, dormait encore. Un Silphe attaché à la Belle prolongeait son repos, \& avait conduit à fon lit le Songe du matin, qui voltigeait sur sa tête, \& la couvrait de ses ailes.

La Belle croit voir un Jeune homme, plus brillant que n'est un Petit-maitre le jour d'une cérémonie, s'avancer dans sa ruelle. À cet aspect, quoiqu'en songe, elle rougit, ce jeune homme, qui était un Silphe, approche alors de son oreille les lèvres séduisantes, \& lui parle en ces mots:

Ô la plus belle des mortelles! Ô toi, les délices \& l'objet des désirs de mille habitants de l'air! si jamais dans l'enfance ton esprit fut ému de ce que ta nourrice t'enseigna au sujet des esprits aériens, prête l'oreille à ma voix \& sois docile.

Connais d'abord ton excellence \& ta grandeur, ne borne point la vue aux objets terrestres \&matériels. II est des vérités secrètes, ignorées des orgueilleux Philosophes, \& révélées seulement aux vierges \& aux enfants. L'incrédulité rebelle n'ajoutera point de foi à celles que je vais t'annoncer; il n'est donné qu'à la beauté \& qu'à l'innocence de les croire. Apprends donc, que des légions innombrables d'esprits t'environnent sans cesse. Cette milice légère de la région inférieure de l'air, quoiqu'invisible à tes yeux, t'accompagne partout, même aux cercles \& aux spectacles: pense à cet aérien cortège, \& tu no verras plus qu'avec mépris un Seigneur suivi de deux pages.

Notre antiquité est égale à celle du Monde: nous fûmes autrefois renfermés dans les plus beaux corps de femmes, mais nous passâmes ensuite de ces corps terrestres dans des corps aériens.

$\mathrm{Ne}$ crois pas que, lorsque les femmes meurent, leurs goûts meurent avec elles: elles les conservent toujours. Si elles ne jouent plus, elles regardent avec plaisir les cartes qu'elles ont aimées: la vue d'un jeu d'ombre les divertit \& les amuse. Si elles ne brillent plus dans leurs chars, elles aiment au moins à voir des équipages magnifiques; leurs âmes retournent toujours à leur premier élément dont elles empruntaient leur caractère. Les Femmes fières \& hautaines deviennent des Salamandres, \& s'élèvent toujours avec le feu, leur éternel séjour: celles qui ont été douces \& complaisantes, vont habiter les eaux \& coulent comme elles; elles boivent avec les Nymphes le thé élémentaire. Les Prudes transformées en Gnomes, descendent dans les entrailles de 
The Rape of the Lock de Alexander Pope y la primera (re)traducción al español...

la terre, \& vont de tous côtés, cherchant à faire du mal. Les vaines\&. les coquettes, changées en Silphes, voltigent \&folâtrent dans les airs. Mais, apprends quel est notre privilège: dégagés des liens mortels, nous pouvons à notre choix changer de forme \& de sexe, \& caresser les femmes belles \& chastes, qui méprisent les terrestres amours. Nous les garantissons de pièges qu'on leur rend dans les bals \& dans les mascarades nocturnes; nous les préservons de l'ardeur dévorante des téméraires amants: en vain on les lorgne pendant le jour, en vain on chuchete avec elles dans les ténèbres; nous les rendons froides \& dédaigneuses, même lorsque l'occasion favorable les invite à la volupté, que la danse les anime, que la musique leur amollit le cœur, enfin ce qu'on appelle ici-bas la sagesse d'une femme, n'est que l'inspiration de son Silphe.

Il y en a quelques-unes destinées par le Ciel aux embrassements des Gnomes. Ce sont d'ordinaire celles qui sont idolâtres de leur beauté. Dirigées par ces esprits jaloux, qui fomentent leur orgueil, elles méprisent les hommes qui leur font la cour; elles dédaignent leurs hommages \& leurs présents. Les Gnomes s'appliquent sans cesse à détourner les flatteuses idées qui pourraient faire impression sur elles. Lorsqu'un Seigneur, par exemple, sait briller à leurs yeux l'Hermine \& la Jarretière, ou qu'elles entendent prononcer les mots séducteurs de Duc \& de Milord, c'est alors que les Gnomes redoublent leurs soins.

D'autres Gnomes se donnent un autre emploi; ils président aux regards des coquettes, ils apprennent aux jeunes filles à conduire habilement leurs yeux; ils sont cause que leurs joues se couvrent à propos d'une rougeur de commande, tandis que leurs cœurs palpitent à la vue d'un joli homme. Les Silphes ont des vues plus délicates \& plus épurées. On croit souvent qu'une jeune personne égare, c'est qu'on ignore les desseins mystérieux du Silphe qui la guide; il la conduit comme par la main, dans un labyrinthe, au milieu des amants \& des amours. Quelquefois, pour la guérir d'une folie, il lui en inspire une autre. Par exemple, quelle fille tendre \& reconnaissante ne serait pas gagné par un présent magnifique offert adroitement, si un autre galant plus habile, ne lui donnait le bal, n'effaçait le souvenir du présent? Lorsque Florio parle, quelle beauté résisterait à son langage séducteur, si en même tems le beau Damon, sans être aperçu, ne lui serrait la main? 


\section{Ángeles García CALDERón/ Emilia María SÁNCheZ JimÉNEZ}

Ce sont là les soins favorables des Silphes. Ils conduisent tout avec habileté. Toujours attentifs à la conservation de l'honneur des femmes, ils opposent finement à de beaux cheveux, d'autres qui ne le sont pas moins, \& à la haute taille, la grâce \& le bon air. Ils combattent les plumets par d'autres plumets, \& les équipages par d'autres équipages. Enfin, tout ce qui est capable de séduire, est repoussé par des charmes plus puissants. Les mortels aveugles appellent légèreté \&coquetterie, ce qui n'est l'effet que de la sage conduite des Silphes.

Je suis de ce nombre: mon nom est Ariel, je te protège, \& je veille sur toi.

Il n'y a pas longtemps que, parcourant le vaste espace des airs, je vis dans le miroir de ton étoile dominante (le diraije?) je te vis menacée d'un funeste accident. Avant que le Soleil se couche, tu en ressentiras les redoutables effets: mais quel sera ce malheur; comment, \& de quelle part il doit venir; quelles suites il doit avoir: les Cieux ne me l'ont point révélé. Veille sur toi, fille chaste; ni ma vigilance, ni mes soins, ne peuvent te soustraire aux arrêts du Destin; sois donc toi-même attentive, \& surtout garde-toi de l'Homme. Il dit;\& alors Mirine, qui ne pouvoir plus supporter le long sommeil de sa Maîtresse, sauta sur le lit \& aboya, \& vint à bout de la réveiller. Si la renommée ne nous a pas trompés, tes premiers regards, ô Belinde, tombèrent sur un billet doux.

À peine commençait-elle de lire, \&d'y voir des plaies, des peines, des martyres, des ardeurs, qu'elle oublia son songe. Elle sort du lit à demi-nue, \& s'approche d'une table où mille vases d'argent étaient placés \& disposés dans un ordre mystérieux. Alors, vêtue de blanc, \& la tête nue, elle adora attentivement les puissances du Monde: une céleste image paraît dans un miroir, elle fixe ses yeux sur elle, c'est l'unique objet de ses pieux regards. Une Prêtresse inférieure, dans une humble attitude, est à côté de l'autel où la vanité préside.

Celle-ci commence les sacrés rites: alors se découvrent de précieux trésors, sources d'ornements\& de beautés pour la Déesse. On voit briller dans de petits coffres les perles \& les pierres les plus précieuses des Indes; les parfums de l'Arabie sortent des flacons d'or qui les renferment; la tortue \& l'éléphant unisse transforment en peignes; les épingles \&les aiguilles sont rangées en escadrons: ici l'on 
The Rape of the Lock de Alexander Pope y la primera (re)traducción al español...

voit confondus, la poudre, la pâte, la Bible, \&les billets doux.

Déjà l'impérieuse beauté prend ses armes, \&. à chaque instant son visage acquiert de nouveaux agréments; les grâces se réveillent, le sourire en est plus doux, l'éclat du teint nait insensiblement, les yeux brillent d'une lumière plus vive. Les Silphes s'empressent autour d'elle: ils ornent sa tête, arrangent ses cheveux, donnent un bon air à sa manche, étalent sa jupe. Sylvie s'applaudit d'une adresse qui n'est pas la sienne ${ }^{7}$ (Arkstée; Merkus 1763 : 327-337).

Antes de proceder al análisis contrastivo de la versión francesa y su traducción al español, procede una breve comparación entre el primer canto del original de Pope y su traducción francesa, lo que nos arrojará luz sobre el traductor francés y su modo de proceder, defendido en su prólogo.

Lo primero que hay que destacar es la forma de escritura, una en verso (el original) y otra en prosa (la traducción); el primer canto de Pope consta de 148 versos, que en la versión francesa se distribuyen en diecinueve párrafos.

Con respecto a su versión el traductor francés explica en el tercer párrafo de su prólogo a qué cánones se va a ajustar: una traducción muy literal, en la que no se ha añadido ni quitado; según él, las diferencias que pueden encontrarse entre las dos son pequeñas, y se deben a las normas lingüísticas de cada lengua, ya que cuando se traduce es necesario preferir expresiones equivalentes a las aparentemente similares. Veamos si lo que afirma en su prólogo es cierto, transcribiendo las dos primeras estrofas del original, equivalentes a los dos primeros párrafos de la versión francesa:

\begin{tabular}{l|l|}
\hline What dire offence from am'rous causes springs, & Je chante une cruelle offense causée par l'Amour, \&un \\
What mighty contests rise from trivial things, & querelle sérieuse née d'une bardiesse badine. Muse, $j$ \\
I sing-This verse to Caryl, Muse! is due: & consacre ces vers à Tirsis, \&uje me flatte que Belind \\
This, ev'n Belinda may vouchsafe to view: & daignera les lire. Quoique je traite de petites choses, $j$ \\
Slight is the subject, but not so the praise, & mériterai de grands éloges, si l'une m'inspire, \& si l'autr \\
If she inspire, and he approve my lays. & m'applaudit. \\
Say what strange motive, Goddess! could compel & Ô Déesse, dis-moi quel étrange motif porta un jeun \\
A well-bred lord t' assault a gentle belle? & Seigneur à attaquer une Belle. Apprends-moi quell \\
O say what stranger cause, yet unexplor'd, & cause encore plus extraordinaire, força la Belle à résiste \\
Could make a gentle belle reject a lord? & aujeune Seigneur. Peut-ily avoir tant de dureté dans un \\
In tasks so bold, can little men engage, & ceur tendre, \& tant de courage dans un Petit-maître? \\
And in soft bosoms dwells such mighty rage? &
\end{tabular}

${ }^{7}$ La traducción francesa añade cuatro notas sobre los silfos y alusiones a pasajes de Virgilio y Estacio. 


\section{Ángeles García CALDERÓN / EMILIA MARÍA SÁNCHEZ JimÉNEZ}

La primera estrofa está bien traducida, con la salvedad de que él traductor cambia el nombre de Caryl por el de "Tirsis". En la segunda el vocablo Lord es traducido en un caso por "jeune Seigneur", y en otro por "Peti-maitre". Aun tratándose de una traducción correcta, creemos que el verso habría propiciado un acercamiento y exactitud más propia con el original, como puede verse en nuestra propuesta:

\footnotetext{
La ofensa motivada por un ardiente amor, que por cosas triviales pudo causar discordias, canto aquí, ¡oh Musa! Caryl: te dedico estos versos; y puede que Belinda me conceda el leerlos: aunque el tema es liviano, pero no la alabanza, si ella es quien me inspira, y es él quien lo aprueba.

¡Oh Diosa! Di: ¿qué extraño motivo impulsaría a un señor de linaje a acosar a una dama? ¿O qué causa aún más rara, hasta ahora ignorada, podría hacer que esta Venus a un Lord rechazara? ¿Pueden los petimetres tener tanta osadía, senos tan delicados albergar tanta ira?
}

Tan sólo una breve conclusión referida a la elección de la prosa por parte del traductor francés: la poesía puede y debe traducirse en verso, es decir en la misma forma de escritura en la que la concibió su autor; eso es lo lógico y deseable, a no ser que en casos muy concretos (poesía filosófica, por ejemplo) el verso no llegue a explicitar totalmente el pensamiento del texto original. Siempre parece preferible traducir la poesía en verso, antes que optar por otro tipo de escritura, ya que parece lógico que el traductor se adapte a su original y no lo cambie. Pero en el caso que nos ocupa, y dado que el modelo en que se basa la retraducción española es francés, el traductor español ha seguido fielmente esta versión olvidándose del original de Pope.

\section{La retraducción anónima al español de 1839}

La obrita, que cuenta con 40 páginas, lleva por título: El bucle arrebatado, poema heroico-cómico en cinco cantos del célebre Pope. Traducido del francés por... Madrid: Imprenta de Omaña, 1839. 
The Rape of the Lock de Alexander Pope y la primera (re)traducción al español...

En el Prólogo, que comprende las páginas 3 y 4, el anónimo traductor aclara que no posee el original inglés y que ha traducido de una versión francesa en prosa $^{8}$.

Para llevar a cabo el análisis de la retraducción española, absolutamente fiel a la traducción francesa de Pope, tanto en el prólogo como en los cantos nos centraremos en dos aspectos:

$1^{\circ}$. Comparando la estructuración u organización interna del francés y de la retraducción al español.

$2^{\circ}$. Señalando a) los errores morfosintácticos (proliferación de leísmos, laísmos y loísmos, uso incorrecto de las preposiciones, uso inadecuado de los tiempos verbales); b) los errores léxico-semánticos (en este apartado tratamos específicamente de tres tipos de "desviaciones" o variaciones en la traducción, que se encuentran en todos los textos, tanto en prosa como en verso: omisiones, adiciones y alteraciones ${ }^{9}$ ); c) errores debidos a la influencia de la lengua francesa (fundamentalmente galicismos) ${ }^{10}$. Veamos el prólogo y el primer canto, que nos marcará la pauta de los restantes:

\section{PRÓLOGO ${ }^{11}$}

Veinte años de edad contaba el célebre Alejandro Pope, cuando produjo este interesante poema. - Fundado en un argumento trivial, parecía que no debiera inventar hasta el punto de designarle los mejores críticos como uno de los primeros poemas burlescos: más todo lo suple la fecunda imaginación del poeta inglés. - Una aventura acaecida a Madam Fermor en el año 1712, nada menos que sobre la

\footnotetext{
${ }^{8}$ Dionisio Hidalgo cita la obra, en su Diccionario General de Bibliografía Española, del siguiente modo: "El bucle arrebatado, poema heróico-cómico en cinco cantos del célebre Pope. Traducido del francés por... Madrid, 1839, Imprenta de Omaña. Lib. de A. González. El objeto moral de este poema, según la misma frase del autor, se reduce a divertir a las jóvenes discretas, y hacerlas reír de las debilidades de su sexo. Lleva un prólogo del traductor" (1872: 244).

${ }^{9}$ Estas "estrategias de traducción" son variables según los teóricos de la traducción es, sin duda a causa de la dificultad que entraña su delimitación; utilizaremos la terminología que García Yebra defendiera en múltiples foros universitarios como la regla de oro de la traducción y que consiste en tres procedimientos usuales: no omitir, no añadir, no adulterar. Digamos que estas denominaciones (omisiones, adiciones y sustituciones) en realidad no se diferencian de las recomendadas por otros autores clásicos como J. P. Vinay y J. Darbelnet, G. Vázquez-Ayora, P. Newmark, etc. (transposición, modulación, amplificación, explicitación, reducción, etc.).

${ }^{10}$ Ello no es óbice para que, en caso de ser necesario, recurramos al texto original de Pope.

11 Tanto la transcripción del Prólogo como la del Primer Canto están adaptados al español actual; dejarlos en su ortografía original implicaría una lectura farragosa en bastantes palabras, sobre todo los cambios de s en $x$ (estensión, estraño, escelencia), los de g en $j$ (muger, lisongeras, mogigatas), como a la falta de acentos de algunas íes (oir), cuando sí lo llevan las aes o las oes.
} 


\section{Ángeles García CALDERÓN/ Emilia María SÁNCheZ JiMÉNEZ}

pérdida de un bucle, ha suministrado al poeta tanta riqueza y originalidad de ideas y situaciones, tanta diversidad de caracteres, cuanto ha acertado a engrandecer tan fútil suceso con todo el interés de una epopeya bien conducida, de una crítica delicada, cuyo objeto moral se reduce, expresándonos con la misma frase del autor, a "divertir a las jóvenes discretas, y hacerlas reír de las debilidades de su sexo."

Si hubiéramos de disertar detenidamente sobre esta creación original, diríamos de ella entre otras cosas, lo que en la introducción a la Ilíada traducida por nuestro autor, dice él mismo de Homero, siguiendo el juicio de varios autores griegos y latinos, en especial de Veleyo Patérculo."Homero, dice, poseyó en grado eminente el don de la invención... No debe sorprender que se le haya tenido siempre por el más grande de todos los poetas, puesto que a todos ha sobrepujado en lo que es el primer fundamento de la poesía." Mas como por una parte el público siempre juzga de las obras por el efecto que hacen en su imaginación, cuya regla es más infalible que las de todos los preceptistas; y por otra los literatos apreciaran el mérito de esta obra en toda la extensión de su justo valor, me abstengo de hacer sobre ella prolijos y oficiosos comentos. No tengo noticia de que se haya traducido al español este poema, entre tantas obrillas como se han dado a conocer entre nosotros -La celebridad del Rizo arrebatado de Pope, avivaba más y más nuestros deseos por leerle; no poseíamos el inglés, pero se nos había designado la mejor traducción francesa hecha en prosa con la mayor fidelidad y exactitud. Y habiéndonos parecido la inspiración de tanto mérito, no hemos dudado darla a conocer entre nosotros, en tanto que otro se dedica a trasladarla del original con acierto y maestría.

\section{CANTO PRIMERO}

Canto una cruel ofensa nacida del amor, y los tristes efectos de un arrojo festivo.

Inspírame, o musa, estos versos a la bella Tirsis consagrados; que espero que Belinda se digne leerlos.

Aunque no son grandes las hazañas que yo celebre, grandes serán los elogios, si Tirsis me anima, si Belinda me aplaude. Reveladme, o sacro Numen, qué extraño impulso convirtió el ánimo delicado de un joven lord en ofensa de una beldad; qué fuerza aun más extraña movió el ánimo de una dama 
The Rape of the Lock de Alexander Pope y la primera (re)traducción al español...

para hacer resistencia a tan osado caballero ¡Es posible que en el pecho de un petimetre pueda caber tanta dureza!!!

El astro del día penetraba unas cortinas blancas, y con tímidos rayos tentaba por abrir unos ojos que habrían de eclipsarle. Ya los perrillos falderos sacudían sus lánguidas orejas: ya los desvelados amantes dejaban el cansado lecho, y el sol había ya corrido la mitad de su vía. Tres veces las pantuflas azotaran el suelo tres veces llamaran las esquilas, y las muestras por el dedo oprimidas hicieran oír su argentino sonido.- Empero, la hermosa Belinda tendida muellemente sobre la pluma de su lecho, aun gozaba del profundo sueño, que le guardara un silfo, allí atraído con los encantos de su hermosura; un silfo conducido por el sueño de la mañana, que revoloteaba en torno de la cabeza de Belinda, derramando sobre ella adormideras y mil flores, y mañana, y cubriéndola con sus alas.

La bella cree ver un joven en sus ensueños, elegante y aderezado, cual en día de ceremonia, acercarse a ella por el estrecho espacio que media entre la cama y la pared: en esto colora el rostro de nuestra joven una encarnada tinta de rubor; más jay! Que el joven representado es un silfo, el cual acerca al oído de Belinda sus seductores labios, y le dice: ¡Oh joven, entre todas las mortales la más hermosa! ¡vos que sois las delicias y el caro objeto de mil habitadores del aire! Si en los tiernos años de la infancia jamás se hubo de alterar vuestro pecho, por los cuentos de duendes que os refiriese la nodriza, prestad grato oído a mi voz, y sed dócil à mis consejos. No limito vuestros ojos a objetos terrestres... materiales... pues conozco demasiado vuestra excelencia y sublimidad. Hay verdades secretas, que ignoran los orgullosos filósofos, y que solo están reveladas a las doncellas y a los niños. No dará crédito a las que voy a descubriros la rebelde incredulidad, porque solo a la belleza é inocencia es dado creerlas.

Mirad, pues, como de continuo os cercan innumerables legiones de espíritus. Esta ligera milicia de la región inferior del aire, en tertulias, en espectáculos, do quien os acompaña: piensa, o Belinda, en esta aérea corte, y de hoy más miraras con aire de desprecio a un gran señor seguido de dos pajes. Nuestra antigüedad es la del mundo. En un principio fuimos encerrados en los más bellos cuerpos de mujeres; más luego pasamos de cuerpos terrestres a cuerpos aéreos No creíais que muerta la mujer mueren sus 


\section{Ángeles García CALDERÓN/ Emilia María SÁNCheZ JiMÉNEZ}

gustos: no: que eternamente los conserva. Esta no juega, pero aun mira con placer las cartas, y la vista solo de un juego de hombre la divierte y deleita. -Aquella no brilla en su carroza, pero el estruendo de magníficos equipajes la enajena, y cada cual vuelve siempre el ánimo al primitivo elemento que formó su carácter. Las soberbias y altaneras se transforman en salamandras, cuya mansión es la esfera del fuego, do se arrebatan. Las dulces y complacientes van a habitar las aguas, fluyen como ellas, y beben con las ninfas el té elementar. Las mojigatas transformadas en Gnomides, penetran en las entrañas de la tierra, y ven por doquier el modo de hacer mal. Las vanas y coquetas en sílfides convertidas, caracolean y juguetean por los aires. Nosotros, empero, gozamos de un privilegio sobrehumano. Libres de mortales cadenas, podemos a nuestro antojo elegir de forma y sexo, y acariciar las jóvenes castas y bellas, que desprecian los amores terrenos; asegurémoslas de cuantos lazos se les tienda en los bailes y mascaradas nocturnas: Las preservamos del fuego devorador de los temerarios amantes, ora de día las contemplen, ora de noche las dirijan seductoras frases. En vano el baile las anima, en vano las mueve a ternura la música; que siempre frías, siempre desdeñosas las ostentamos. En resumen, lo que se llama en la tierra el honor, la discreción de una mujer no es otra cosa que la inspiración de su silfo.

Hay igualmente jóvenes destinadas por el cielo a las caricias de los gnomos. Estas son por lo común idólatras de su hermosura. Dirigidas por aquellos espíritus celosos que fomentan en su pecho un orgullo vano, premian con el desprecio las más rendidas atenciones, homenajes y presentes de sus sensibles caballeros. Los gnomos se dedican de continuo a distraerlas de aquellas lisonjeras ideas que pudieran tal vez cautivarlas: $\mathrm{y}$ cuando un caballero por ejemplo ostenta su vista el armiño y la jarretiera, o cuando hieren sus oídos las seductoras palabras de Duque ó Milord, los gnomos redoblan sus esfuerzos por apartarlas del peligro. De otros cargos se confían también los gnomos: ellos presiden las miradas de las coquetas; enséñanlas a mover sus ojos con destreza, y a que se cubran de propósito sus mejillas de un encarnado que imprime superioridad y respeto; en tanto que en la presenciad de un joven agraciado palpitan sus pechos. 
The Rape of the Lock de Alexander Pope y la primera (re)traducción al español...

Los silfos tienen el ojo más largo y más fino... profundizan con más acierto el espíritu de las damas. Las más veces se juzga a una joven descaminada... distraída... porque se ignora los misteriosos designios del silfo que la guía: Condúcela sin esfuerzo por un laberinto de amantes y de amores poblado: las más veces, para curarla de un capricho, otro nuevo le inspira. Un magnífico presente, por ejemplo, con cierta discreción ofrecido, qué joven tierna y reconocida no ganara, si otro más hábil galán, dando un suntuoso baile en memoria de la dama, no diese a un tiempo ocasión al olvido de la primera fineza. Cuando Florio abre sus labios qué beldad resistiera a sus dulces recuestas, si el bello Damon no la estrechase a tiempo una mano con destreza suma.

Estos son los primeros cuidados de los silfos. ¡Tan hábilmente dirigen las acciones de las damas! Siempre celosos por la conversación de vuestro honor sagrado, oponen diestramente a cabellos hermosos, no menos hermosos cabellos, y al alto talle la gracia y elegancia del mediano talle. Ora unos petimetres por otros, ora unos aderezos por otros desairados quedan, y todo cuanto es capaz de seducir se ve contrarrestado por atractivos más poderosos. Y los ciegos mortales entiende por ligereza y coquetería, lo que solo es efecto de la discreción de una mujer conducida por los silfos.

De esta raza somos el jefe, nuestro nombre es Ariel; este silfo que te ama, vela de continuo en tu protección.

No ha mucho tiempo, amada mía; no ha mucho tiempo que, recorriendo el vasto espacio de los aires, vi en el disco de vuestra dominante estrella... ¡oh Belinda! yo mismo os vi amenazada de un acontecimiento fatal. Sí; más pronto que el sol esconda sus rayos en el seno de los mares habéis de sentir los terribles efectos de los hados. Empero cual pueda ser el vuestro, de qué linaje y origen, los cielos aun no se han dignado revelarme. Alerta, casta joven: velad sobre vuestra persona. - Ni mi celo, ni mis cuidados podrán sustraeros a los decretos del destino. Cuidad, no obstante, de evitar el peligro que os amenaza, y guárdate sobre todo del hombre.

Dijo: y al punto Mirina que ya no podía sufrir más tiempo el pesado sueño de su ama, salta sobre el lecho, ladra y logra despertarla al punto. Si no miente la fama, no bien se 


\title{
Ángeles García CALDERón/ Emilia María SÁNCheZ JimÉNEZ
}

\begin{abstract}
abrieron vuestros ojos, oh Belinda, cuando fueron à dar con un billete.

No bien comienza a leer, y a sentir los plañidos, las penas, los martirios y los ardores del escrito, cuando olvida el ensueño, y saltando del lecho medio desnuda, se acera a una mesa do se hallaban mil vasos de oro colocados con cierto misterio. En hábito blanco y desnuda la cabeza, adora respetuosamente las grandezas del mundo: En un espejo aparece una imagen celestial: en ella fija sus ojos nuestra joven; y este es el único objeto de sus piadosas miradas. Una sacerdotisa al servicio de nuestra deidad, se mira en humilde actitud al lado del ara donde la vanidad preside Dase principio à los ritos; descúbrense al punto ricos tesoros de adornos y aderezos. Las perlas y piedras más preciosas de las Indias brillan en pequeños cofrecillos: los perfumes de la Arabia de unos botes de oro se exhalan: la tortuga y el elefante en peines se transforman; los alfileres y agujas se hallan por escuadrones colocados; os polvos, la pasta, la Biblia y los billetes amorosos se confunden.

Ya la imperiosa deidad toma sus armas; y su rostro adquiere por momentos nuevos encantos; sus gracias se renuevan, su sonrisa es más dulce; el lustre de su tez se aumenta; y sus ojos brillan más vivos. Los silfos en su derredor andan solícitos; adornan su cabeza, ordenan sus cabellos, dan cierta elegancia a su marcha, ostentan su vestido... y Silvia se huelga de contemplar a Belinda, creyendo tener parte en su elegancia y aderezo.
\end{abstract}

\subsection{Estructura de la traducción francesa y de la retraducción al español}

La traducción francesa, incluida en la obra de referencia, abarca desde la página 321 a la 364 y consta de tres apartados: a) Una dedicatoria a Mme Arabella Fermor, representada en el poema por Belinda. b) Un "Préface du traducteur", en el que exalta las virtudes de Pope, "le premier Poète moderne de l'Angleterre", y del poema original, que mostrará a los lectores cómo los ingleses son capaces de alcanzar un alto grado de "plaisanterie, satyre délicate, et élégant badinage". El elogio llega a ser tan grande que el traductor afirma que no hay en la lengua francesa nada tan ingenioso como el poema de Pope, a pesar de tener el autor sólo veinte años al escribirlo. Justifica luego su elección en prosa aclarando que le habría resultado más difícil traducirlo en verso, y que su resultado en prosa poética le permite llegar a la imaginación del lector cual si verso fuera. Espera y desea el traductor que un poema que está ornado por la invención, el acertado 
The Rape of the Lock de Alexander Pope y la primera (re)traducción al español...

esbozo, el orden, las imágenes, lo maravilloso y todo aquello que constituye la verdadera poesía constará con la aquiescencia no sólo de las damas, sino de todos aquellos que leen un poema burlesco con ojos y mente abierta para observar las cualidades, que no son en suma diferentes a las de los poemas serios, ya que en él se han seguido fielmente los principios de la epopeya. c) Los cinco cantos de que consta el poema original, y de los cuales analizaremos algunos aspectos de forma general, y el primer canto de modo específico.

La retraducción española consta de cuarenta páginas que incluyen: a) Un Prólogo, muy inferior a su modelo francés, en el que en su última parte alaba la traducción francesa, según le han dicho, como la mejor de las llevadas a cabo en prosa, "por su fidelidad y exactitud". b) Los cinco cantos de su modelo, que también analizaremos en algunos aspectos de forma general, para centrarnos en el primero de modo específico.

\subsection{Errores morfosintácticos}

\subsubsection{Proliferación de leísmos, laísmos y loísmos}

$\mathrm{Al}$ tratar sobre el controvertido y debatido problema en nuestro tiempo de los leísmos, laísmos y loísmos (que en el tiempo en que escribía nuestro anónimo traductor no era tal, y que aparece profusa y abundantemente en los textos traducidos.) es muy pertinente la opinión del prestigioso lexicógrafo Ahumada Lara (1999: 93):

La Real Academia de la lengua no ha mostrado demasiadas reticencias hacia el leísmo o uso de le por lo en función de complemente directo. Es más, entre 1796 y 1872, le fue el pronombre recomendado por la institución para el complemento directo masculino, con excepción del neutro lo. Sólo a partir de 1854 tolera la alternancia le / lo, es decir, reconoce el empleo etimológico de lo como complemento directo. Jaén, como el resto de Andalucía y Aragón, distingue con toda nitidez el empleo etimológico de los pronombres átonos lo, la y le.

Los ejemplos que encontramos en la retraducción española (con mención de lo correcto entre corchetes, y cita de la página entre paréntesis), son los siguientes ${ }^{12}$ :

${ }^{12} \mathrm{El}$ subrayado indica la no pertinencia de la palabra utilizada. 


\title{
Ángeles García CALDERÓN / EMILIA MARÍA SÁNCHEZ JimÉNEZ
}

\begin{abstract}
“Avivaba más y más nuestros deseos por leerle[lo]" (p. 4); "otro nuevo le $[$ la] inspira" (9);"Un esclavo rebelde osa retarle[lo]" (21); "le [lo] hiere, y le hace vomitar su negra alma" (22); "se arroja sobre él y le $[$ [lo] rinde"; "se acerca a ella con todo respeto y veneración, y la le $]$ dice" (29); "Comprendo, amada Belinda, la[le] dice Talestris" (31); " $\mathrm{y}$ que una vez separado de tan hermosa cabeza, no brillará de hoy más creciendo: juro llevarle $[$ lo, el bucle en mi diestra (32)"; "En vano se pretende convencerle[lo]" (35); "y con una mirada le $[\mathrm{lo}]$ hiere"; "y con un dedo le $[\mathrm{lo}]$ derriba en tierra" (38); "que solo el ojo poético ha podido divisarle [lo] y seguirle[lo] al cielo" (39); "y dirigiéndola[le] sus votos"
\end{abstract} (40).

Algunos usos de laísmo en el texto (ㅁa dice, dirigiéndola) nos llevan a pensar que el anónimo traductor del texto francés podría localizarse en el centro de España, más concretamente en Madrid y su zona de influencia, donde los hablantes suelen utilizar esa forma del pronombre.

\subsubsection{Uso incorrecto de las preposiciones}

Se pueden detectar errores en el uso de algunas preposiciones, ya se trate de incluir unas y otras no, o bien de utilizarlas equivocadamente unas en lugar de otras ${ }^{13}$; veamos los usos indebidos, o su falta, según su aparición en el texto:

"El astro del día penetraba [por] unas cortinas blancas" (5); "allí atraído con [los] encantos de su hermosura" (6); "vela de continuo en [por] tu protección" (9); "yo mismo os vi amenazada de [por] un acontecimiento fatal" (10); "y Silvia se huelga de [en] contemplar a Belinda" (11); "y en torno de [a] ella reina la alegría" (15); "entretanto que yo velo sobre [por] su perrilla Mirina" (17); "Allí los ministros británicos deciden de [sobre] la suerte de los estados de Europa" (19); "siete combatientes se preparan a [para] la pelea" (20); "El invencible espadilla es el primero a [en] señalarse" (21); "ambos desordenan y aterran [a] las fuerzas enemigas" (22); "Los silfos vuelan solícitos en torno de [a] Belinda" (23); "El vigilante Ariel intenta penetrar [en] los designios del barón"; "y confuso, cede al destino, y de [por]

13 A pesar de que ya en la Gramática de la Lengua Castellana de la Real Academia Española (De Ibarra 1771). 
The Rape of the Lock de Alexander Pope y la primera (re)traducción al español...

su ignorancia suspira" (24); "Corre el rumor entre el vulgo,

[de] que este bucle fue elevado a la esfera de la luna" (39).

\subsubsection{Uso inadecuado de los tiempos verbales y errónea elección de vocablos o frases}

En ocasiones el traductor al español no vierte acertadamente los tiempos verbales que utiliza su modelo francés, utiliza reflexivos inadecuadamente, o se sirve de palabras no del todo apropiadas, como podemos ver en los siguientes ejemplos al comparar las dos traducciones ${ }^{14}$ :

Trois fois les pantoufles avoient frappé le plancher; trois fois les sonnettes avaient appelé, \& les montres pressées du doigt avoient fait entendre leur son argentin. (32).

Tres veces las pantuflas azotaran el suelo tres veces llamaran las esquilas, y las muestras por el dedo oprimidas bicieran oír su argentino sonido. (5).

Les Silphes ont des vues plus délicates \& plus épurées. On croit souvent qu'une jeune personne égare, c'est qu'on ignore les desseins mystérieux du Silphe qui la guide; il la conduit comme par la main, dans un labyrinthe, au milieu des amants \& des amours. Quelquefois, pour la guérir d'une folie, il lui en inspire une autre. (335).

Los silfos tienen el ojo más largo y más fino... profundizan con más acierto el espiritu de las damas. Las más veces se juzga a una joven descaminada... distraida... porque se ignora los misteriosos designios del silfo que la guia: Condúcela sin esfuerzo por un laberinto de amantes y de amores poblado: las más veces, para curarla de un capricho, otro nuevo le inspira. (9).

Déjà l'impérieuse beauté prend ses armes, \&. à chaque instant son visage acquiert de nouveaux agréments; les grâces se réveillent, le sourire en est plus doux, l'éclat du teint naît insensiblement, les yeux brillent d'une lumière plus vive. (337).

Ya la imperiosa deidad toma sus armas; y su rostro adquiere por momentos nuevos encantos; sus gracias se renuevan, su sonrisa es más dulce; el lustre de su tez se aumenta; y sus ojos brillan más vivos. (11).

\footnotetext{
${ }^{14}$ En la traducción francesa citamos de la edición de 1763: CEuvres diverses de Pope, traduites de l'anglais.
} 


\section{Ángeles García CALDERÓN / EMILIA MARía SÁNCHEZ JiMÉNEZ}

\subsection{Errores léxico-semánticos}

A lo largo de los cinco cantos el autor de la versión española omite, añade y altera palabras y frases de su modelo francés, aunque la mayor parte de las veces se trata de variaciones de poco calado, llevadas a cabo posiblemente para una mejor comprensión del texto en su idioma; veamos algunos ejemplos de estas variaciones:

\subsubsection{Omisiones}

Lo más relevante en el apartado de omisiones lo hallamos en la supresión de las cuatro notas que incluye la traducción francesa, sobre los silfos y alusiones a pasajes de Virgilio y Estacio, ya que ninguna de ellas está en el texto español. Asimismo, la cita alusiva a los Epigramas de Marcial, en cabeza de la versión francesa, está ausente en la versión española.

\subsubsection{Adiciones y alteraciones}

Utilizadas las dos quizá para aclarar el texto francés, un examen minucioso de los párrafos correspondientes entre las dos versiones descubre algunas adiciones y alteraciones, que comienzan ya desde la primera línea: "une cruelle offense causée par l'amour" (332) / "Una cruel ofensa nacida del amor" (5). Veamos dos ejemplos:

Le Soleil perçoit au travers de rideaux blancs \&par de timides rayons essayait d'ouvrir ces yeux qui le devaient éclipser. Déjà, les chiens favoris secouaient leurs oreilles; les amants, qui se plaignent de ne dormir jamais, commençaient à s'éveiller: il était midi. (332).

El astro del día penetraba unas cortinas blancas, y con tímidos rayos tentaba por abrir unos ojos que habrian de eclipsarle. Ya los perrillos falderos sacudian sus lánguidas orejas: ya los desvelados amantes dejaban el cansado lecho, y el sol habia ya corrido la mitad de su vía. (5).

Fácilmente se puede apreciar la diferencia entre los dos textos, pues en el español se añade (lánguidas, desvelados) y se cambia toda la parte final.

Il n'y a pas longtemps que, parcourant le vaste espace des airs, je vis dans le miroir de ton étoile dominante (le diraije?) je te vis menacée d'un funeste accident. Avant que le 
The Rape of the Lock de Alexander Pope y la primera (re)traducción al español...

Soleil se couche, tu en ressentiras les redoutables effets. (336).

No ha mucho tiempo, amada mía; no ha mucho tiempo que, recorriendo el vasto espacio de los aires, vi en el disco de vuestra dominante estrella... joh Belinda! yo mismo os vi amenazada de un acontecimiento fatal. Sí; más pronto que el sol esconda sus rayos en el seno de los mares habéis de sentir los terribles efectos de los bados. (10).

El retraductor repite y añade para enfatizar; sustituye luego la reflexión entre paréntesis por puntos suspensivos; la sugerencia de la puesta de sol es adornada en el texto español.

3.3.3. Errores debidos a la influencia de la lengua francesa en el traductor

Como bien indica el historiador, poeta y filólogo venezolano Rafael María Baralt, autor del primer diccionario de galicismos del español (Baralt 1995) y primer latinoamericano en ocupar un sillón en la Real Academia de la Lengua Española, el galicismo "consiste en dar a una palabra española significación que tiene en francés otra que se le parece" (Baralt 1995); citamos tres casos de los más llamativos:

Les montres pressées du doigt avoient fait entendre leur son argentin. (332).

Traducido del siguiente modo:

Las muestras por el dedo oprimidas hicieran oir su argentino sonido.

(5).

La traducción correcta debería ser "argentado", es decir un sonido claro, una voz argentada, pero nunca argentino.

Lorsqu'un Seigneur, par exemple, sait briller à leurs yeux l'Hermine \& la Jarretière. (334-5).

$Y$ cuando un caballero por ejemplo ostenta a su vista el armiño y la jarretiera. (8).

La traducción correcta sería "jarretera", en cualquiera de sus dos acepciones: 1. f. Liga con su hebilla con que se ata la media o el calzón por el jarrete. 2. f. 


\section{Ángeles García CALDERÓN / EMILIA MARÍA SÁNCHEZ JimÉNEZ}

Orden militar instituida en Inglaterra, llamada así por la insignia que se añadió a la Orden de San Jorge, que fue una liga.

El vocablo "billet doux" es utilizado dos veces ya en el primer canto, en los dos contextos siguientes:

Si la renommée ne nous a pas trompés, tes premiers regards, ô Belinde, tombèrent sur un billet doux. (336).

Ici l'on voit confondus, la poudre, la pâte, la Bible, \& les billets doux. (337).

En ninguno de los dos casos la traducción propuesta se ajusta al sentido del término francés "nota, misiva o carta amorosa", palabra que penetró en Inglaterra desde la lengua francesa. Las traducciones al español no aclaran el texto:

Si no miente la fama, no bien se abrieron vuestros ojos, ob Belinda, cuando fueron à dar con un billete. (10).

Los polvos, la pasta, la Biblia y los billetes amorosos se confunden. (11).

\section{Conclusiones}

La similitud entre la traducción francesa y su retraducción al español puede justificarse por el cotejo frase por frase, de los ejemplos que hemos llevado a cabo.

Que el traductor español ${ }^{15}$ eligiera la lengua francesa para traducir, y no el original inglés era un hecho bastante común en el siglo XIX en España; a ello contribuiría su buena comprensión de esa lengua, y no de la inglesa, lo cual lo lleva a veces a cometer flagrantes galicismos, como hemos podido ver en los ejemplos mencionados.

Pero, donde el traductor muestra su plena "formación francesa" es en una expresión concreta, muy de uso actual y que ya, posiblemente sin tener plena conciencia de ello, el traductor español utiliza: nos referimos a la expresión "lo que es", que el traductor usa al citar a Homero en el prólogo ("lo que es el primer fundamento de la poesía", p. 4). Estructura de uso prácticamente inevitable en nuestra época, y que va penetrando incluso en la lengua escrita, su procedencia debe establecerse en la "muletilla" o "palabra baúl" francesa "ce qui est", utilizada

15 Así parece deducirse por el empleo de laísmos. 
The Rape of the Lock de Alexander Pope y la primera (re)traducción al español...

por los hablantes galos para enlazar una frase con otra, pero que no tiene significación alguna ${ }^{16}$. Por poner un ejemplo fácilmente comprensible, es muy común oír esta estructura en español, cuando un cocinero explica en televisión como elabora su guiso: "añádasele lo que es un tomate, luego lo que es un pimiento...".

\section{Referencias bibliográficas}

BARALT, Rafael María, Diccionario de galicismos o sea de las voces, locuciones y frases de la lengua francesa que se han introducido en el habla castellana moderna, Prólogo de Juan Eugenio Hartzenbuch. Madrid: Visor Libros, 1995.

AHUMADA LARA, Ignacio, El habla popular de Jaén en la literatura. Jaén: Editorial Jabalcuz, 1999.

DE IBARRA, Joachin, Gramática de la Lengua Castellana de la Real Academia Española. Madrid: Impresor de Cámara de S.M., M.DCC. LXXI.

Hidalgo, Dionisio, Diccionario General de Bibliografía Española. Tomo Quinto. Madrid: Imprenta de J. Limia y G. Urosa, 1872.

POITEVIn, Prosper, Petits poètes français, depuis Malherbes (sic) jusqu'à nos jours, avec des notices biographiques et littéraires sur chacun d'eux. Tome Premier. Paris: Auguste Desrez, 1838.

Pope, Alexander, The Poems of Alexander Pope, one-Volume Edition of the Twickenham Tex with Annotations, ed. de J. Butt. London: Yale University Press, 1963.

—, Euvres diverses de Pope, traduites de l'anglais. Nouvelle édition, Augmentée de plusieurs pièces et de la vie de l'auteur: Avec de très belles Figures en taille douce. Tome Second. Amsterdam: Arkstée et Merkus, 1763 (1754).

—, El bucle arrebatado, trad. anónima. Madrid: Omaña, 1839.

-, El rizo robado, trad. de Graciliano Afonso Naranjo. Las Palmas de Gran Canaria: Imprenta de M. Collina, 1851.

—, El robo del bucle, trad. de César Gilberto Saldaña Fernández. Lima: Pontificia Universidad Católica del Perú, 2002.

—, El robo del rizo, trad. de A. Lastra y Á. García Calderón. En: Ensayo sobre el hombre y otros escritos de Alexander Pope. Madrid: Editorial Cátedra, 2017.

-, El rizo robado, trad. de Enrique García Díaz. Disponible en línea en: https://es.scribd.com/document/168930042/el-rizo-robado-pdf. [Fecha de consulta: 24 de marzo de 2018].

${ }^{16}$ Lo más parecido que existe en nuestra lengua, sería la repetición de una frase para ganar tiempo y pensar en lo que se va a decir. 
Ángeles García CALDERÓN/ Emilia María SÁNCHEZ JiMÉNEZ

Torralbo Caballero, Juan de Dios, “Alberto Lista, traductor de Alexander Pope: El imperio de la estupidez”. En: Hermeneus, 20, 2018, pp. 509-531. 